\title{
FEATURES OF DEVELOPMENT AND IMPLEMENTATION OF COURSES OF THE EDUCATIONAL FIELD «MATHEMATICS» IN DISTANCE EDUCATION SYSTEM
}

(C) 2016

\author{
E.L. Makarova, candidate of pedagogical sciences, \\ associate professor of the Chair of Computer Science, Applied Mathematics and Teaching Methods \\ O.I. Pugach, candidate of pedagogical sciences, \\ associate professor of the Chair of Computer Science, Applied Mathematics and Teaching Methods \\ Samara State University of Social Sciences and Education, Samara (Russia)
}

\begin{abstract}
Effective application of distance technologies, even at the level of individual courses in most universities is faced with a number of organizational, methodological problems. The final design of the regulatory framework the problem of implementation of these technologies in the field of theoretical research and experimental work in the practical implementation of the plane. The authors consider a wide range of problems arising from the mass introduction of e-learning in educational practice, their classification on various grounds. When the authors of the work are based on practical experience in the development of the course «Mathematical Foundations of Computer Science» for students training areas «Teacher Education» profiles «Informatics» and «Computer Science and Foreign Language» on the basis of a learning management system Moodle. Also studied a number of aspects related to the characteristics of the studied subject area (in «Mathematics» example of educational area). We formulate the necessary conditions for effective use of e-learning technologies. These conditions, from the point of view of the authors, speakers, among others participated in the implementation of the university administration, the formation of a uniform by the level of the basic mathematical training a group of students, the formation of a thesaurus (semantic web) course in the classroom working with students, as well as a phased approach to solving complex text assignments, requiring the construction of a formal mathematical model in the subject area. We offer some simple criteria for evaluating the effectiveness of (increased performance and students' motivation, optimization of time working teachers, reducing the number of chronic debtors in the discipline).

Keywords: distance learning; courses; introduction; educational area «Mathematics»; cost effectiveness; curriculum; work program; organization of independent work of students; examination of teaching materials; innovation; introduction of distance learning technologies; electronic educational resources.
\end{abstract}

\section{УДК 347.779}

\section{КОМПЛЕКСНАЯ ОЦЕНКА ГОТОВНОСТИ ВЫПУСКНИКОВ МАГИСТРАТУРЫ К ПРОФЕССИОНАЛЬНОЙ ДЕЯТЕЛЬНОСТИ}

(C) 2016

В.Н. Михелькевич, доктор технических наук, профессор кафедры психологии и педагогики, профессор кафедры электропривода и промышленной автоматики

П.Г. Кравцов, кандидат технических наук, доцент кафедры электропривода и промышленной автоматики Самарский государственный технический университет, Самара (Россия)

Аннотация. В соответствии с требованиями Федеральных государственных образовательных стандартов высшего образования в результате освоения программы магистратуры у выпускника должны быть сформированы общекультурные, общепрофессиональные и профессиональные компетенции по направлению подготовки, а образовательная организация обязана обеспечивать гарантию качества подготовки выпускников. Однако образовательные стандарты не регламентируют процедуру оценивания качества освоения образовательных программ, а лишь устанавливают общие требования к ней. Поэтому для аттестации обучающихся на соответствие их персональных достижений требованиям основной образовательной программы магистратуры многие вузы самостоятельно создают фонды оценочных средств, позволяющие оценить знания, умения и уровень приобретенных компетенций. В статье анализируются сложившиеся в педагогической практике системы оценивания, основанные на определении уровней освоения отдельных компонент профессиональных компетенций. Отмечается, что таким системам нередко присуща высокая трудоемкость и недостаточная комплексность при решении задачи оценивания готовности выпускников магистратуры к профессиональной деятельности. Предложено альтернативное инновационное решение этой задачи за счет использования фонда комплексных контрольных заданий в качестве диагностического инструментария при итоговой аттестации магистрантов. Это соответствует содержащимся в образовательных стандартах указаниям на то, что разрабатываемые оценочные средства должны позволять установить не только качество сформированных у обучающихся компетенций, но и степень общей готовности выпускников к профессиональной деятельности. Представлен опыт проектирования и использования в учебном процессе фонда комплексных контрольных заданий на кафедре электропривода и промышленной автоматики Самарского государственного технического университета.

Ключевые слова: выпускники магистратуры; профессиональные компетенции; комплексные контрольные задания; готовность к профессиональной деятельности; комплексная оценка готовности. 
Михелькевич В.Н., Кравцов П.Г.

Комплексная оценка готовности выпускников магистратуры..

13.00.00 - педагогические науки

Подготовка инженерных кадров в высших учебных заведениях опирается на квалификационные характеристики специалистов, где учитываются две стороны их будущей деятельности - функциональная и предметная. Компетентностные модели таких специалистов, адаптированных к конкретным условиям профессиональной деятельности, связаны с различными наборами компетенций, которые позволяют сформировать и развить у будущих выпускников необходимые им профессиональные и профессиональноличностные качества $[1 ; 2 ; 3]$.

Наиболее полно личностные характеристики студентов, их профессионально-значимые качества, наклонности и способности к определенному виду профессиональной деятельности формируются и диагностируются в процессе функционально-ориентированной подготовки специалистов. Методологической основой функционально-ориентированной подготовки студентов и выпускников в технических вузах является представление о функциональной структуре инженерной деятельности и соответствующей ей трехкомпонентной структуре профессионально-образовательных программ [4]. При этом содержание профессиональной подготовки в общем случае представляется в виде трех логически и структурно взаимосвязанных компонентов или подсистем: базовая (фундаментальная) подготовка по направлению (специальности); функциональная инженерная специализация; предметно-отраслевая инженерная специализация. Необходимость широкой фундаментальной подготовки специалистов в техническом вузе обусловлена объективными требованиями к видам профессиональной деятельности и качествам личности специалиста, которые позволяют ему эффективно выполнять требования профессии и вместе с тем создают условия для развития личности самого работника. Под функциональной инженерной специализацией понимается совокупность дополнительных знаний и умений, а также приобретенных студентами общекультурных и общепрофессиональных компетенций для выполнения определенных инженерных функций по своей специальности или направлению (профилю) подготовки. Функциональная специализация обусловлена особенностями содержания отдельных видов профессиональной деятельности и существенными различиями психофизиологических требований, предъявляемых к тому или иному виду инженерного труда: конструктора, исследователя, технолога, оператора сложной автоматизированной установки, технического руководителя и т.П. Предметно-отраслевая инженерная специализация представляет собой совокупность дополнительных знаний, умений и компетенций, необходимых для выполнения инженерных функций в определенной области техники или отрасли производства (автомобилестроение, производство двигателей, нефтехимия и т.д.). Основное назначение функционально-ориентированной подготовки специалистов состоит в создании условий для свободного развития личности студентов, значительном сокращении сроков трудовой адаптации выпускников, формировании у них во время обучения в вузе свойств функциональной гибкости и компетентности.
Основу готовности и способности выпускников к выполнению различных видов профессиональной деятельности составляют профессионально-значимые качества личности. Этот термин объединяет в себе два понятия: профессионализм и личностные качества, т.е. совокупность психофизиологических, эмоционально-волевых, характерологических качеств личности, которые в наибольшей степени удовлетворяют требованиям данной профессии. Тщательное определение перечня обязанностей, которые должны выполнять специалисты в различных видах инженерного труда, проявляя при этом свою компетентность, и совмещение этого перечня с требованиями к профессионально-значимым личностным качествам, необходимым для успешной профессиональной деятельности, задают направленность организации учебного процесса в формировании соответствующих компетенций у студентов и достижении требуемой компетентности выпускников. [5; 6].

В соответствии с требованиями Федеральных государственных образовательных стандартов высшего образования в результате освоения программы магистратуры у выпускника должны быть сформированы общекультурные, общепрофессиональные и профессиональные компетенции по направлению подготовки, а образовательная организация обязана обеспечивать гарантию качества подготовки выпускников. Поскольку при использовании компетентностного подхода в качестве результата образования рассматривается не сумма усвоенной учебной информации, а способность (готовность) обучающихся и выпускников действовать в изменяющихся производственных ситуациях, решать профессиональные задачи различной степени сложности, то образовательные организации должны указанную способность (готовность) измерять и оценивать. Однако образовательные стандарты не регламентируют процедуру оценивания качества освоения образовательных программ, а лишь устанавливают общие требования к ней. В частности, вузам предлагается для аттестации студентов на соответствие их персональных достижений поэтапным или конечным требованиям соответствующей основной образовательной программы самостоятельно создавать фонды оценочных средств, включающие типовые задания, контрольные работы, тесты, позволяющие оценить знания, умения и уровень приобретенных компетенций. И если оценочные действия в отношении знаний и умений давно стали неотъемлемым элементом повседневной педагогической деятельности, то обоснование и выбор критериев, измерение и оценка уровней сформированности приобретенных компетенций и готовности выпускников к профессиональной деятельности являются одной из недостаточно исследованных, но крайне важных проблем в профессиональном образовании.

Существуют различные взгляды на систему оценивания результативности подготовки выпускников. Сторонники инновационных подходов придерживаются позиции, что качество предоставляемых образовательных услуг должны в первую очередь оценивать их потребители - студенты и работодатели, а не преподаватели вузов [7; 8]. При таком подходе результативность функционально-ориентированной по- 
Михелькевич В.Н., Кравцов П.Г.

дготовки специалистов следует характеризовать двумя интегральными показателями качества:

- степенью удовлетворенности выпускников условиями для свободного развития их личности во время обучения в вузе и их востребованностью на рынке инженерного труда;

- степенью удовлетворенности предприятий соответствием уровня подготовки молодого специалиста требованиям работодателя по срокам трудовой адаптации выпускников вузов на предприятиях, их функциональной гибкости и компетентности.

Однако указанные показатели качества, строго говоря, можно определить в полной мере лишь после окончания студентами вуза и их одно-, двухлетней работы на предприятиях после трудоустройства. Следовательно, на этапе обучения в вузе оказывается возможным оценить только создание предпосылок, благоприятствующих достижению этих показателей [9]. При этом для формирования необходимых профессионально-личностных качеств у студентов требуется внести определенные изменения в существующие технологии подготовки специалистов технических специальностей и, в частности, включить в процесс подготовки инженерных кадров анализ проблем, возникающих в реальных производственных ситуациях для различных видов профессиональной деятельности, а также изучение алгоритмов и методов решения этих проблем [10].

С другой стороны, вузы не могут игнорировать и традиционные критерии качества подготовки специалистов, которые сложились в системе высшего профессионального образования за многолетнюю практику обучения и выпуска инженерных кадров. Примером могут служить предложенные Н.А. Селезневой и В.П. Беспалько следующие критерии, используемые при итоговой аттестации выпускников технических вузов и характеризующие качество усвоения выпускником нормативной системы деятельности специалиста с высшим образованием определенного профиля [11]:

- полнота (системность) усвоения выпускником нормативной системы деятельности с учетом взаимосвязи и значимости отдельных элементов этой системы, т.е. сформированность системно-деятельностного мышления;

- глубина усвоения выпускником нормативной системы деятельности, измеряемая достигнутым иерархическим уровнем усвоения: репродуктивным, продуктивным, эвристическим или творческим;

- степень научности (степень абстрактности) усвоенной выпускником нормативной системы деятельности специалиста;

- степень автоматизма навыков усвоенной выпускником нормативной деятельности или сформированной необходимой динамичности в ориентировке и принятии решений в проблемных ситуациях.

С учетом изложенного оценивание уровня сформированности компетенций и готовности выпускников к профессиональной деятельности представляет собой сложную многокритериальную задачу определения соответствия результатов обучения требованиям Федеральных Государственных образовательных стандартов высшего профессионального образования и предприятий-работодателей. При этом необходимо учитывать тесную взаимосвязь двух сторон учебного процесса - путей и способов формирования компетенций и методов оценки степени их сформированности. Инновационные формы контроля должны стать своеобразным продолжением методик обучения, позволяя студентам более четко осознавать их достижения и недостатки, корректировать собственную активность, а преподавателю - направлять деятельность обучающихся в необходимое русло.

Вместе с тем в условиях компетентностного обучения разработанные вузами фонды оценочных средств не всегда адекватно отображают требования Федеральных государственных образовательных стандартов, не полностью соответствуют целям и задачам основных образовательных программ магистратуры. Это связано с тем, что еще недостаточно отработан механизм комплексного измерения качества подготовки выпускников вузов, обеспечивающего полноту, системность и взаимосвязанность учета и оценки результатов их учебной деятельности при итоговой аттестации. Обычно профессиональные компетенции измеряются косвенным путем, опосредованно, через уровни сформированности структурных компонент этих компетенций, когда каждая из измеряемых профессиональных компетенций расчленяется на несколько (обычно от трех до пяти) компонент, например на когнитивную, операциональную и деятельностную [12]. В свою очередь, для каждой из этих компонент разрабатываются критерии и показатели сформированности, а также соответствующие средства их измерения. Полученные данные по уровням сформированности компонент затем используются с соответствующими весовыми коэффициентами для расчета интегральных значений профессиональной компетенции. Такой подход представляется достаточно трудоемким, а методики сведения воедино показателей сформированности отдельных составляющих профессиональных компетенций - не всегда обоснованными. Работодатели нередко ставят под сомнение критерии оценки качества подготовки специалистов, принятые в вузах.

В Самарском государственном техническом университете требуемые стандартами фонды оценочных средств для текущей, промежуточной и итоговой аттестации студентов и выпускников разрабатываются, утверждаются и применяются на единой методологической основе в соответствии со следующими представлениями о ключевых ценностях оценивания:

- оценивание должно быть валидным (объекты оценки должны соответствовать поставленным целям учебной дисциплины);

- оценивание должно быть надежным (необходимо использовать единообразные согласованные критерии или стандарты);

- оценивание должно быть объективным (разные студенты должны иметь равные возможности получения справедливой оценки);

- оценивание должно быть развивающим (фиксировать, что могут студенты и как им улучшить свои результаты);

- оценивание должно быть своевременным (постоянно поддерживающим развивающую обратную связь); 
Михелькевич В.Н., Кравцов П.Г.

Комплексная оценка готовности выпускников магистратуры...

13.00.00 - педагогические науки

- оценивание должно быть эффективным (выполнимым, но не забирать много времени у преподавателей и студентов).

При этом важнейшее значение придается совершенствованию оценочных средств, используемых при итоговой аттестации выпускников [13; 14]. К ним, в частности, относятся программа итогового междисциплинарного государственного экзамена по направлению подготовки (специальности); комплект экзаменационных заданий и критерии их оценки; методические материалы, определяющие процедуру проведения экзамена и защиты выпускной квалификационной работы; критерии оценки соответствия уровня подготовки выпускников требованиям Федеральных государственных образовательных стандартов высшего образования по результатам защиты выпускных квалификационных работ.

Значимость объективной и достоверной оценки уровня готовности выпускников к практической профессиональной деятельности непрерывно возрастает. Федеральные государственные образовательные стандарты высшего образования устанавливают, что вузами должны быть созданы условия для максимального приближения системы оценивания и контроля компетенций обучающихся по основным образовательным программам магистратуры к условиям их будущей профессиональной деятельности. С этой целью, кроме преподавателей конкретной дисциплины, в качестве внешних экспертов должны активно использоваться работодатели (представители заинтересованных предприятий, учреждений). Наиболее рациональным выходом из сложившейся ситуации представляется совместная разработка вузами и предприятиями-работодателями оценочных средств, а также совместный мониторинг качества освоения образовательных программ в процессе функциональноориентированной подготовки специалистов $[15 ; 16]$.

Сочетая инновационный и традиционный подходы к оценке результативности функционально-ориентированной подготовки выпускников, кафедра электропривода и промышленной автоматики Самарского государственного технического университета совместно с работодателями разработала оценочные средства для итогового междисциплинарного государственного экзамена по специальности (профилю) «Электропривод и автоматика промышленных установок и технологических комплексов» [17]. Эта разработка выполнена на базе метода аналитической профессиографии, включающего в себя описание профессиональных функций, профессиональных задач и признаков исполнения задач. Каждая профессиональная задача - это обобщенная модель профессиональной ситуации, с которой специалист может встретиться в своей практической деятельности, а признаки исполнения задачи - это эталон ее решения. Подобные профессиональные задачи и эталоны их решения представляют собой комплексные квалификационные функционально-ориентированные контрольные задания. Они охватывают все основные диверсифицированные программы подготовки к выполнению различных видов профессиональной деятельности (проектно-конструкторской, производственно-технологической, организационно-управленческой, научно-исследовательской, монтажно-наладоч- ной, сервисно-эксплуатационной), требующие различных профессионально-значимых качеств и различных уровней сформированности компетенций у студентов и выпускников [18; 19]. Поэтому для каждого вида профессиональной деятельности составляются соответствующие профессиональные задачи, учитывающие функциональную специализацию и цели функционально-ориентированной подготовки обучающихся.

При составлении заданий были использованы описания конкретных производственных ситуаций, возникающих в электротехнической отрасли при выполнении различных видов инженерной деятельности (инженерных функций). Поскольку содержание вариативных учебных модулей гибкого учебного плана является различным при подготовке специалистов к разным видам профессиональной деятельности, то и оценочные средства являются вариативными и отражают специфику функциональных инженерных специализаций [20]. Контрольные вопросы составлены таким образом, чтобы по ответам на них, отражающим дидактически адаптированный опыт решения учебно-профессиональных задач и производственных ситуаций, можно было судить о степени освоения экзаменуемым учебного материала и о соответствии экзаменуемого тому или иному предъявляемому требованию в части его готовности к предстоящей профессиональной деятельности.

Валидность содержания комплексных контрольных заданий, методики их использования и полученных на государственных междисциплинарных экзаменах комплексных оценок сформированности компетенций была подтверждена экспертными исследованиями, в которых приняли участие преподаватели вуза и представители работодателей - руководители и высококвалифицированные специалисты предприятий электротехнической отрасли. Разнообразие контрольных задач дает возможность выполнить оценку готовности выпускников к предстоящей работе по всем основным видам профессиональной деятельности. Практический опыт использования фонда комплексных контрольных заданий позволил установить, что время, затрачиваемое на проведение аттестационных процедур, сокращается в 2-2,5 раза по сравнению с использованием традиционных оценочных средств и методик их применения. Дальнейшие исследования проблемы комплексного оценивания уровней сформированности готовности студентов к решению различных по степени сложности и виду инженерной деятельности профессиональных задач в процессе текущего контроля и промежуточной аттестации будут способствовать повышению качества подготовки обучающихся в технических вузах.

\section{СПИСОК ЛИТЕРАТУРЫ:}

1. Активные и интерактивные образовательные технологии (формы проведения занятий) в высшей школе: учебное пособие / сост. Т.Г. Мухина. Н. Новгород: ННГАСУ, 2013. 97 с.

2. Вербицкий А.А., Ларионова О.Г. Личностный и компетентностный подходы в образовании. Проблемы интеграции. М.: Логос, 2009. 336 с.

3. Никифорова С.В. Профессионально-значимые качества личности специалиста: сущность, содержа- 
Михелькевич В.Н., Кравцов П.Г.

ние и методика выявления // Вестник Самарского государственного технического университета, серия «Психолого-педагогические науки». 2009. № 1 (11). C. $72-79$.

4. Михелькевич В.Н., Кравцов П.Г. Организация функционально-ориентированной подготовки специалистов в техническом вузе: учебное пособие. Самара: Изд-во СамГТУ, 2009. 102 с.

5. Антонов Г.М., Михелькевич В.Н., Попов Г.М. Деятельностный подход к формированию у курсантов личностных профессионально-значимых качеств // Правовое и духовно-нравственное воспитание российского офицерства: Материалы Всероссийской науч.-практ. конф. Самара: Самарский юридический институт ФСИН, 2015. С. 160-171.

6. Бочкарева Т.С., Воликов В.А. Практико-ориентированные оценочные средства по специальности «Автосервис» // Синергетика природных, технических и социально-экономических систем: Сб. статей XIII-й Международной науч. конф. Тольятти: Изд-во ПГУС, 2015. С. 44-47.

7. Качалов В.А. Стандарты ИСО 9000 и проблемы управления качеством в вузах: Записки менеджера качества. М.: ИздАТ, 2001. 127 с.

8. Крокинская А.К., Трапицын С.Ю. Студент как «потребитель образования»: содержание категории // Высшее образование в России. 2015. № 6. С. 65-75.

9. Вербицкий А.А., Рыбакина Н.А. Методологические основы реализации новой образовательной парадигмы // Педагогика. 2014. № 2. С. 3-14.

10. Никифорова С.В., Михелькевич В.Н. Case-stu$d y$ инжиниринга технических объектов - эффективный инструментарий формирования и оценки качества сформированности у студентов профессиональных компетенций // Вектор науки Тольяттинского государственного университета, 2013. № 1 (23). С. 353-357.

11. Селезнева Н.А. Качество высшего образования как объект системного исследования. Лекциядоклад. М.: Исследовательский центр проблем качества подготовки специалистов, 2001. 79 с.

12. Рябинова Е.Н.,, Титов Б.А., Павлова И.О. Измерительные процессы в дидактике гуманитарных дисциплин // Синергетика природных, технических и социально-экономических систем: Сб. статей XII Международной науч. конф. Тольятти: Изд-во ПГУС, 2014. С. $174-183$

\section{COMPREHENSIVE ASSESSMENT OF THE MA GRADUATES' READINESS FOR PROFESSIONAL WORK}

(C) 2016

V.N. Mikhelkevich, doctor of technical sciences, professor of the Chair of Psychology and Pedagogy, professor of the Chair of Electric Drive and Industrial Automation

P.G. Kravtsov, candidate of technical sciences, associate professor of the Chair of Electric Drive and Industrial Automation Samara State Technical University, Samara (Russia)

Abstract. In accordance with the requirements of Federal state educational standards of higher education as a result of the development of the graduate program a graduate should develop general cultural, general professional and professional competences in the field of training and educational organization is obliged to provide a guarantee of the quality of graduates. However, educational standards do not regu-late the procedure of evaluation of quality of educational programs mastering, but merely set out com-mon requirements for it. Therefore, for evaluation of students in accordance with their personal achievements to the requirements of the basic educational program of magistracy many universities make their own funds assessment tools to evaluate knowledge, skills and level of item competencies. The article analyzes the existing in the teaching practice assessment systems, based on development levels of separate proСамарский научный вестник. 2016. № 2 (15) 
fessional competence components. The authors note that such systems often have a high complexity and a lack of complexity in solving the problem of estimation of master's graduates' readiness for professional work. The authors propose an alternative innovative solution to this problem through the use of the complex control fund as a diagnostic tool for the final certification of under-graduates. This corresponds to the guidelines of the educational standards and our evaluative tools as-sess the quality of developed students' competences as well as the degree of general readiness of grad-uates for professional work. The authors present the experience of designing and use of the complex control tasks fund in the educational process of the Chair of Electric Drive and Industrial Automation of Samara State Technical University.

Keywords: alumni; professional competence; complex control tasks; readiness for professional work; comprehensive readiness assessment.

УДК 378

\title{
СРАВНИТЕЛЬНЫЙ АНАЛИЗ УДОВЛЕТВОРЁННОСТИ КУРСАНТОВ ПРОФЕССИОНАЛЬНОЙ ПОДГОТОВКОЙ В ВЕДОМСТВЕННОМ ВУЗЕ ФСИН РОССИИ
}

О.В. Ощепкова, доктор педагогических наук, профессор кафедры пенитенциарной психологии и педагогики

И.В. Попов, кандидат педагогических наук, доцент кафедры управления и информационно-технического обеспечения деятельности УИС Самарский юридический институт Федеральной службы исполнения наказаний, Самара (Россия)

\begin{abstract}
Аннотация. Удовлетворённость обучаемых высших учебных заведений своей учебно-профессиональной деятельностью в сегодняшней реальности является одним из ключевых показателей, диагностирующим качество подготовки специалистов, эффективности формирования профессиональной компетентности. Удовлетворенность предполагает личностное включение обучаемого в образовательный процесс, которое неразрывно связано с оценочным отношением личности к качеству тех или иных объектов, к условиям жизни и деятельности, в том числе и к самому себе. Оценка же является важнейшим элементом эмоциональной сферы человека, эмоции стимулируют мотивацию к деятельности. Под удовлетворенностью мы понимаем интегральную характеристику, включающую мотивационную и эмоциональную сферы личности; это оценочное отношение обучаемых к выполняемой им деятельности, её результатам и условиям осуществления. Профессиональная подготовка курсантов осуществляется в специфических условиях их нахождения на казарменном положении на территории ведомственного вуза. В интегральную характеристику удовлетворенности обучаемых профессиональной подготовкой были включены три критерия: удовлетворённость учебным процессом; удовлетворённость внеучебной деятельностью; удовлетворённость взаимоотношениями. В свою очередь, первый критерий содержит удовлетворённость: 1) организацией учебного процесса; 2) уровнем профессионализма преподавателей; 3) качеством своей подготовки. Во второй критерий мы ввели показатели удовлетворённости: 1) организацией работы кружков, секций, клубов; 2) организацией спортивно-массовых мероприятий; 3) организацией мероприятий, помогающих формированию профессиональной компетентности будущего офицера уголовно-исполнительной системы. Третий критерий предполагает удовлетворенность отношениями с преподавателями, с коллективом, с непосредственным руководством. Анкетирование курсантов 2 и 5 курсов Самарского юридического института ФСИН России показало, что в целом к 5 курсу обнаруживается положительная тенденция в оценке удовлетворенности профессиональной подготовкой. Отдельного дополнительного анализа требует критерий «удовлетворённость внеучебной деятельностью», поскольку к 5 курсу удовлетворённых работой кружков, секций, клубов меньше трети от общей численности курса. По третьему критерию обнаружена некоторая сложность во взаимоотношениях с непосредственным руководством (с командирами строевых подразделений), что также должно стать предметом специального дополнительного рассмотрения.

Ключевые слова: удовлетворенность; удовлетворенность профессиональной подготовкой; высшее профессиональное образование; специфика подготовки курсантов ведомственного вуза; критерии и показатели удовлетворенности курсантов профессиональной подготовкой.
\end{abstract}

Проблема удовлетворённости учебно-профессиональной деятельностью обучаемых высших учебных заведений в сегодняшней реальности является одной из важных и актуальных. Объясняется это тем, что реформирование системы образования, которое неразрывно связано с необходимостью повышения его качества, возможно только посредством решения одной из основных задач системы профессионального образования - профессионально-личностного развития студентов наряду с формированием их профессиональной компетентности. Это требование может быть успешно и эффективно реализовано только в случае полного личностного включения обучаемого в образовательный процесс, в котором актуализируются личностные смыслы, активизируются мотивы самореализации, доминируют положительные эмоции и чувства - словом, то, что, по нашему мнению, вбирает в себя понятие «удовлетворенность». «Удовлетворенность работой представляет собой набор положительных и отрицательных ощущений человека, показывающих, как он оценивает свою работу» [1, c. 67].

Проблема удовлетворённости учебной деятельностью сейчас активно разрабатывается, о чём свидетельствует большое количество публикаций. В частности, удовлетворённость многими исследователями 